\title{
Initial Surgical versus Non-Surgical treatments for advanced hypopharyngeal cancer: a meta-analysis with trial sequential analysis
}

Jie Cui

Guangzhou Medical University Affiliated Cancer Hospital

Liping Wang

Hainan Medical University

Jinsong Piao

Guangzhou Medical University Affiliated Cancer Hospital

Haiyan Huang

Guangzhou Medical University Affiliated Cancer Hospital

Weiquan Chen

Guangzhou Medical University Affiliated Cancer Hospital

Zhen Chen

Shunde Hospital of Southern Medical University

Hong Yang

Guangzhou Medical University Affiliated Cancer Hospital

Xiaojun Tan

Guangzhou Medical University Affiliated Cancer Hospital

Jiansheng Li

Guangzhou Medical University Affiliated Cancer Hospital

Genglong Liu ( $\square$ Iglong3@mail2.sysu.edu.cn )

Affiliated Cancer Hospital of Guangzhou Medical https://orcid.org/0000-0002-9163-4396

\section{Research article}

Keywords: surgical, chemoradiotherapy, advanced hypopharyngeal cancer, survival, trial sequential analysis.

Posted Date: January 8th, 2020

DOI: https://doi.org/10.21203/rs.2.20267/v1

License: (9) (i) This work is licensed under a Creative Commons Attribution 4.0 International License. Read Full License

Version of Record: A version of this preprint was published at International Journal of Surgery on October 1st, 2020. See the published version at https://doi.org/10.1016/j.ijsu.2020.04.059. 


\section{Abstract}

\section{Background}

There is no consensus whether either initial surgical or non-surgical treatments should be the standard treatment pattern to advanced hypopharyngeal cancer. The aim of the meta-analysis was systematically and quantitatively to compare the relative efficacy between initial surgical and non-surgical therapies in patients with advanced-stage hypopharyngeal carcinoma.

Methods

A comprehensive search was performed in PubMed, the ISI Web of Knowledge, the Cochrane Library, and Embase databases from inception through to April 10, 2019.Citation screening, data abstraction and quality assessment were performed in duplicate. Meta-analysis with trial sequential analysis (TSA) were used to assess the primary and secondary outcomes. In addition, we used the Grading of Recommendations Assessment Development and Evaluation (GRADE) to evaluate the certainty of the body of evidence.

Results

A total of 17 trials was appraised with 2539 patients that were in compliance with inclusion and exclusion criterion. Pooled analyses indicated patients receiving primary surgical and non-surgical therapy did not significantly differ in overall survival (OS) (relative risk [RR] $=1.04,95 \%$ confidence interval $[\mathrm{Cl}]=0.94$ to 1.15), with TSA inconclusive. Additionally, patients treated with primary surgical experienced an increased disease free survival (DFS) probability compared with non-surgical treatment (RR 1.20, 95\% Cl=1.05 to1.37), while TSA is inconclusive. Notably, non-surgical management did have a beneficial efficacy on larynx preservation ( $\mathrm{RR} 0.48,95 \% \mathrm{Cl}=0.33$ to 0.70 ), and TSA also provided conclusive evidence. GRADE indicated the level of evidence was low or very low for primary or secondary outcomes.

\section{Conclusion}

The results of our meta-analysis indicated compared to surgical treatments, non-surgical therapy for patients with advanced hypopharyngeal carcinoma appear to equivalent efficacy, and it offers an opportunity to preserve laryngeal function. Due to inconclusive evidence by TSA, further investigation with larger randomized clinical trials (RCTs) using modern approaches should be undertaken to verify the results of this metaanalysis.

\section{Background}

As an aggressive malignancy, hypopharyngeal cancer is less popularity than other head and neck cancers (HNC), on behalf of $3-5 \%$ of all $\mathrm{HNC}$. According to the World Health Organization (WHO) definition, hypopharynx included four sites, namely the pyriform sinus, the post-cricoid region, the posterior wall of the hypopharynx, and the hypopharyngeal aspect of the aryepiglottic fold ${ }^{2}$.Usually, these patients at diagnosis present advanced stage, due to the lack of obvious symptoms in early-stage disease and prone to extensive infiltration and growth in submucosa. In addition, more than $60 \%$ patients occurred nodal metastasis in ipsilateral ${ }^{3}$ and up to $40 \%$ of them appeared contralateral occult nodal tumor deposits ${ }^{4}$ on presentation, which rendered formidable therapeutic challenges to ablative and reconstructive surgeons as well as clinical oncologists. The estimated 5-year overall survival rate for treated stage III and IV hypopharyngeal cancer patients varies between approximately $15 \%$ and $40 \%$, depending on tumor-related factors, patient-related factors, and treatment approaches ${ }^{5}$.

Retrospect to the 1990s, curative surgical resection followed by postoperative radiotherapy was recognized as the cornerstone treatment for advanced hypopharyngeal cancer. Over the past decade, with the advancement of radiotherapy and chemotherapy, especially the application of concurrent chemoradiotherapy and targeted drugs, organ preservation and the local control rate have been remarkably improved ${ }^{6}$. A vast of trials, both retrospective and prospective, have revealed that organ preservation using definitive chemoradiotherapy with surgery reserved for salvage is a receivable alternative to surgery with similar survival outcomes in HNC, including hypopharyngeal carcinoma that merely account for a smaller subgroup ${ }^{7-9}$.

Regarding the preferred therapeutic option for advanced hypopharyngeal carcinoma, there is no level-one evidence even if the adoption of chemoradiotherapy as a standard of care ${ }^{10}$. The determination to treat continues to be disputable in a locally advanced setting. To resolve these knowledge gaps, we performed a comprehensive meta-analysis with trial sequential analysis (TSA), which better control type I and type II errors, to compare the outcomes of surgical management (primary surgery with either adjunctive radiotherapy or adjunctive chemoradiation) versus non-surgical modalities, including induction chemotherapy with (chemo) radiotherapy and definitive chemoradiotherapy, in patients with advanced hypopharyngeal cancer.

\section{Methods}


This meta-analysis was performed in accordance with Cochrane

Handbook for Systematic Reviews of Interventions ${ }^{35}$ and PRISMA (the Preferred Reporting Items for Systematic Reviews and Meta-Analyses) guidelines ${ }^{36}$.A pre-specified protocol registered at PROSPERO online platform in December 2018 (registry number: CRD42018118563).

\section{Data sources}

A systematic search of electronic databases was performed, including Medline (via the PUBMED interface), ISI Web of Knowledge, the Cochrane Library (via the Ovid interface), and EMBASE. All searches were conducted from inception through to April 10, 2019. All of the pertinent publications was identified by using the following terms and their combinations: (hypopharyngeal or pyriform sinus or post-cricoid), (neoplasm*or tumor* or cancer* or carcinoma* or malignanc*), (surgery or surgical) and (chemotherapy or CRT or chemoradiation or radiotherapy or RT). No language restriction was enforced. Additionally, we manually scanned references of relevant reviews of the literature and retrieved studies. To identify unpublished articles, abstracts from international conferences were inspected for additional pertinent researches.

\section{Eligibility criteria}

Literatures was independently examined by two authors to determine their eligibility for inclusion and exclusion criterion in the meta-analysis, with disagreement finally resolved by consensus. Included literatures satisfied the following PICOS standard (participants, interventions, comparators, outcomes, and study design): 1) Population: adult advanced hypopharyngeal cancer patients; 2) Intervention: surgical management (primary surgical followed by either adjuvant radiotherapy or adjuvant chemoradiation); 3) Comparison intervention: non-surgical modalities(induction chemotherapy followed by (chemo)radiotherapy and definitive chemoradiotherapy); 4) Outcome: outcomes of interest (primary or secondary endpoint ) of the current meta-analysis; 5) Study design: retrospective cohorts or prospective cohorts or randomized clinical trial (RCT). Studies were excluded if they were case reports, letters to the editor, editorials, case series, review articles, and trials with insufficient data (e.g. lack of survival information), even if contacting the corresponding authors.

\section{Data extraction}

The relevant data was independently abstracted by two reviewers from the eligible studies into standardised collection tables for the evidence and outcomes, such as lead author, year of publication, nation, study design, number and percentages of man, age of patients, simple size, percentage of T4 stage, percentage of positive lymph node, percentage of stagelV, percentage of pyriform sinus, follow-up time, treatment modalities, overall survival, disease free survival, and larynx preservation.

If possible, outcome data were separately divided into each subgroup. According to the age were lower or higher than the median of the entire trials, it was classified as "low" or "high" subgroup. The predefined primary endpoint was overall survival (OS) at longest follow-up available. The predefined secondary outcomes were disease free survival (DFS) at longest follow-up available, and larynx preservation.

\section{Quality assessment}

Risk of bias of the eligible trials was independently assessed by two authors, with no affiliation with any of the eligible trials. In cases of eventual divergences by discussion to achieve a consensus or consultation with a third author. Based on the Cochrane Collaboration methods ${ }^{37}$, the methodological quality of randomized controlled trials (RCTs) was assessed. The eligible studies were classified as low quality, or high quality according to the following criteria: 1) when allocation concealment or randomization was considered as a high risk of bias, regardless of the risk of other items, studies were assessed low quality; 2) if both allocation concealment and randomization were considered as a low risk of bias, and all other items were considered as low or unclear risk of bias in a study, studies were considered high quality. Based on the NewcastleOttawa scale, the study quality of observational studies was evaluated. The quality of trials was adjudicated on three broad perspectives: selection, comparability, and exposure/outcome, with four items (one star each), one item (up to two stars) as well as three items (one star each), respectively. In this analysis, studies were judged as high quality if they scored $\geq 7$ stars.

\section{Statistical analyses}

For dichotomous outcomes, relative risk (RR) with 95\% confidence interval ( $\mathrm{Cl})$ was calculated. Between-study heterogeneity by the estimates of diversity $\left(D^{2}\right)$, the inconsistency statistics $\left(\mathrm{I}^{2}\right)$ and visual inspection of the forest plots was evaluated. If a $P$ value $<0.05$ or $I^{2}>50 \%$, substantial heterogeneity was considered existing. We adopted a fixed effects model and when $\mathrm{I}^{2}=0$. If $\mathrm{I}^{2}$ was above zero, we adopted both fixed and random effects models, and used the most conservative estimate being the estimate with the widest $\mathrm{Cl}$ or the point estimate closest to no effect.

Pre- specified subgroups were performed based on study location (western country vs. eastern country), study design (randomized controlled trial vs. cohort), age (> 60 vs. $\leq 60$ ), and study quality (high quality vs. low quality). Analysis was conducted to evaluate whether the difference was statistically significant between the subgroups. In additional, subgroup differences were tested by Chi-square test-that is, whether the observed differences are aligned with chance alone within the subgroups. A low P value or a large Chi-square statistic relative to its degree of freedom construct evidence of heterogeneity beyond chance.

Page 3/16 
Meta-regression analysis was conducted to explore the associations between the primary outcome and characteristics of participants. Factors considered variables included publication year, percentage of male, mean age, simple size, percentage of T4 stage, percentage of positive lymph node, percentage of stagelV, percentage of pyriform sinus, and mean follow-up time. We evaluated publication bias for primary outcomes by funnel plot inspection and the Harbord test, in which 10 or more studies provided data.

All meta-analyses were conducted with RevMan version 5.3 (The Cochrane Collaboration, Copenhagen, Denmark) and Stata version 14 (StataCorp, College Station, Texas, USA). All P values are double-tailed, and the statistical significance was set at 0.05.

\section{Grading the quality of evidence}

Grading of Recommendations Assessment, Development, and Evaluation (GRADE) approach was used to assess the overall quality of evidence for each estimated outcome. According to study design, study quality, precision, consistency, directness and the risk of reporting bias, the overall quality of evidence is graded "high", "moderate", "low" or "very low" for each outcome. The analyses was performed in GRADE Pro-version 3.6 software.

\section{Trial sequential analysis}

We conducted trial sequential analysis (TSA) to explore whether cumulative data were adequately powered to assess outcomes. In this procedure, according to an alpha value set at $5 \%$ to determine significance, we established Z-curves for the primary outcome and secondary outcomes. Using the O'Brien-Fleming alpha spending method, we constructed adjusted significance trial sequential monitoring boundaries, with the hypothesis that a new study was successively added to the meta-analysis when significant testing may have been conducted each time. Based on a pre-defined relative risk reduction or increase of $15 \%$ in each outcomes, the required information size was computed, with the type I error $(\alpha)$ at 0.05 or 0.01 and the power $(1-\beta)$ at 0.90. TSA software version 0.9.5.9 (Centre for Clinical Intervention Research) was used for these analysis ${ }^{38}$.

\section{Results}

\section{Identification of studies}

Figure 1 shows the flowchart for the research selection program. Initially, the PubMed search identified 2,341 trials, the ISI Web of Knowledge 2,760, Cochrane Library 552, and Embase 442. After 3083 were removed as duplicates, 2924 trials were further excluded after titles and abstracts reviewed, and 88 literatures were scrutinized by scanning their full texts. Ultimately, 17 researches ${ }^{11-27}$ met our predefined criteria and were included in the meta-analyses.

\section{Characteristics of the eligible studies}

Table 1 present the main characteristics of selected studies. The 17 studies included two RCTs ${ }^{11,22}$ and fifteen retrospective cohorts ${ }^{12-21,23-27}$, with a total of 2539 patients, and were published from 1994 to 2019. Eight trials were conducted in western countries (eg. France, USA, Croatia, Portugal, The Netherlands), eight in eastern countries (eg. Taiwan, Korea, China), one not available. The simple size varied from 47 to 857 per study, the average age of patients varied between 54.4 and 64 years. Percentages of man, percentage of T4 stage, percentage of positive lymph node, percentage of stagelV and percentage of pyriform sinus, varied widely, with ranging from $78.6-100 \%$, ranging from $4.3-86.7 \%$, ranging from $63.4-91.8 \%$, ranging from $6.6-87.8 \%$, ranging from $50.6-100 \%$, respectively. Mean follow-up periods varied, ranged from $19-92$ months. Table S1 details treatment modalities of the studies included in the meta-analysis. 
Table 1

Baseline characteristics of the studies included in the meta-analysis.

\begin{tabular}{|c|c|c|c|c|c|c|c|c|c|c|}
\hline Study(year) & Nation & $\begin{array}{l}\text { Study } \\
\text { design }\end{array}$ & $\begin{array}{l}\text { Male,No. } \\
(\%)\end{array}$ & $\begin{array}{l}\text { Age }(y) \text {, } \\
\text { average } \\
\text { (range or } \\
\text { SD) }\end{array}$ & $\begin{array}{l}\text { Sample } \\
\text { size }\end{array}$ & $\begin{array}{l}\text { T4, No. } \\
(\%)\end{array}$ & $\begin{array}{l}\text { N+, No. } \\
(\%)\end{array}$ & $\begin{array}{l}\text { Stage IV, } \\
\text { No.(\%) }\end{array}$ & $\begin{array}{l}\text { Pyriform } \\
\text { sinus, } \\
\text { No.(\%) }\end{array}$ & $\begin{array}{l}\text { Follow- } \\
\text { up } \\
\text { (m),mean } \\
\text { (rang) }\end{array}$ \\
\hline $\begin{array}{l}\text { Beauvillain } \\
\text { (1997) }\end{array}$ & France & RCT & $90(97.8)$ & $\begin{array}{l}56(35- \\
69)\end{array}$ & 92 & $4(4.3)$ & $65(70.6)$ & NA & $90(97.8)$ & $\begin{array}{l}92(64- \\
115)\end{array}$ \\
\hline $\begin{array}{l}\text { Chung } \\
(2019)\end{array}$ & Korea & $\mathrm{RC}$ & 249(93.6) & $\begin{array}{l}63.7(41- \\
86)\end{array}$ & 266 & $86(32.3)$ & 242(91\%) & NA & 216(81.2) & $\begin{array}{l}32.9(6- \\
152)\end{array}$ \\
\hline $\begin{array}{l}\text { Harris } \\
(2015)\end{array}$ & USA & $\mathrm{RC}$ & $59(77)$ & $63.6(8.7)$ & 76 & $36(47)$ & $61(80)$ & NA & NA & $\begin{array}{l}30(6- \\
120)\end{array}$ \\
\hline $\begin{array}{l}\text { Huang } \\
(2010)\end{array}$ & Taiwan & $\mathrm{RC}$ & 45(95.7) & $\begin{array}{l}57(40- \\
73)\end{array}$ & 47 & $26(55.3)$ & $33(70.2)$ & $36(76.6)$ & $41(87.2)$ & $19.4(\mathrm{NA})$ \\
\hline $\begin{array}{l}\text { Hung } \\
(2006)\end{array}$ & NA & $\mathrm{RC}$ & $60(100)$ & $58(N A)$ & 60 & $52(86.7)$ & $52(86.7)$ & NA & $35(58.3)$ & 20 (NA) \\
\hline Jang (2016) & Korea & $\mathrm{RC}$ & NA & NA & 177 & NA & NA & NA & NA & 19(NA) \\
\hline Kim (2001) & Korea & $\mathrm{RC}$ & 67(91.8) & $\begin{array}{l}58(25- \\
79)\end{array}$ & 73 & NA & NA & $57(78.1)$ & NA & NA \\
\hline Kim (2016) & Korea & $\mathrm{RC}$ & $86(94.5)$ & $\begin{array}{l}64(36- \\
80)\end{array}$ & 91 & $30(33)$ & $79(86.8)$ & $6(6.6)$ & 73(80.2) & $\begin{array}{l}50(5- \\
141)\end{array}$ \\
\hline Kim (2018) & Korea & $\mathrm{RC}$ & $706(82.4)$ & NA & 857 & $237(27.7)$ & $609(71.1)$ & NA & $434(50.6)$ & NA \\
\hline $\begin{array}{l}\text { Lajtman } \\
(2001)\end{array}$ & Croatia & $\mathrm{RC}$ & $52(85.2)$ & $\begin{array}{l}\text { 64(32- } \\
79)\end{array}$ & 61 & 24(39.3) & $56(91.8)$ & NA & $61(100)$ & NA \\
\hline Lee (2008) & Taiwan & $\mathrm{RC}$ & 71(95.9) & $\begin{array}{l}62(43- \\
76)\end{array}$ & 74 & $31(41.9)$ & $67(90.5)$ & 65(87.8) & $46(62.2)$ & $\begin{array}{l}21(3- \\
132)\end{array}$ \\
\hline $\begin{array}{l}\text { Lefebvre } \\
\text { (1996) }\end{array}$ & France & RCT & 186(95.9) & $\begin{array}{l}55(35- \\
70)\end{array}$ & 194 & $11(5.7)$ & $123(63.4)$ & 71(37) & $152(78)$ & $\begin{array}{l}51(3- \\
106)\end{array}$ \\
\hline Reis (2016) & Portugal & $\mathrm{RC}$ & 142(98.6) & $\begin{array}{l}54.4(34- \\
81)\end{array}$ & 144 & NA & NA & 109(75.7) & 117(81.3) & $\begin{array}{l}36.6(3- \\
110)\end{array}$ \\
\hline $\begin{array}{l}\text { Slotman } \\
(1994)\end{array}$ & $\begin{array}{l}\text { The } \\
\text { Netherlands }\end{array}$ & $\mathrm{RC}$ & 45(83.3) & $\begin{array}{l}\text { 64(43- } \\
90)\end{array}$ & 54 & 17(31.5) & 42(77.8) & NA & $54(100)$ & NA \\
\hline $\begin{array}{l}\text { Vandersteen } \\
\text { (2015) }\end{array}$ & France & $\mathrm{RC}$ & $86(87.8)$ & $\begin{array}{l}62.4(37- \\
87)\end{array}$ & 98 & $38(38.8)$ & $67(68.4)$ & NA & NA & 43(NA) \\
\hline $\begin{array}{l}\text { Zelefsky } \\
\text { (1996) }\end{array}$ & USA & $\mathrm{RC}$ & $44(78.6)$ & $\begin{array}{l}61(36- \\
80)\end{array}$ & 56 & 10(17.9) & $44(78.6)$ & $35(62.5)$ & $38(67.9)$ & NA \\
\hline $\begin{array}{l}\text { Zhang } \\
(2018)\end{array}$ & China & $\mathrm{RC}$ & 112(94.1) & $\begin{array}{l}57(27- \\
78)\end{array}$ & 119 & $52(43.7)$ & 108(90.8) & $86(72.3)$ & $75(63.0)$ & NA \\
\hline
\end{tabular}

\section{Methodological quality of eligible studies}

Figures S1 and S2 shows the quality assessment of the RCTs. To summarize, neither two RCTs reported the blinding of patients and personnel, or the blinding of outcome assessment. On account of other items in RCTs was low bias, two RCTs were adjudicated high quality. Table S2 displays the quality assessment of the cohorts. These results showed that five studies, which was rated as high quality, scored between 7 and 8 points, and the other ten studies, which was considered as low quality, scored below 6 points.

\section{Primary outcomes}

Results of the pooled effect indicated that the difference between non-surgical treatment and initial surgical on overall survival (OS) was not statistically of significance (relative risk [RR] 1.04; $95 \%$ confidence interval $[\mathrm{Cl}] 0.94$ to $1.15 ; \mathrm{I}^{2}=5 \%$ ) (Fig. $2 \mathrm{~A}$ ), and the summary OR and $95 \% \mathrm{Cl}$ were estimated using the random effect model with the widest $\mathrm{CI}$. TSA results indicated that the cumulative Z-curve did not enter the futility area 
(Fig. 2B). The estimated required information size to cross the futility boundaries was 3823 randomized patients. The subgroup analysis did not find any significant differences between subgroups on the basis of study location, study design, age, and study quality (Table 2)

Table2.Subgroup analyses comparing surgical versus non-surgical treatments for

overall survival.

\begin{tabular}{|llllll|}
\hline Subgroup & & No. of studies & RR $(95 \%$ Cl $)$ & Pvalue & Pvalues \\
& & & & & between \\
& & & & & subgroup \\
\hline Study & western country & 8 & $1.13(0.94-1.34)$ & 0.19 & 0.23 \\
location & eastern country & 8 & $0.99(0.88-1.11)$ & 0.85 & \\
Study & RCT & 2 & $1.13(0.61-2.98)$ & 0.46 & 0.51 \\
design & cohort & 15 & $1.03(0.92-1.15)$ & 0.61 & \\
\hline Age & $\leq 60$ & 7 & $1.13(0.96-1.33)$ & 0.15 & 0.73 \\
\cline { 2 - 7 } & $>60$ & 8 & $1.08(0.91-1.29)$ & 0.37 & \\
\hline Study & high quality & 7 & $1.10(0.94-1.29)$ & 0.25 & 0.29 \\
quality & low quality & 10 & $0.98(0.85-1.13)$ & 0.77 & \\
\cline { 2 - 6 }
\end{tabular}

Abbreviations: No.= number of participants, $\mathrm{RR}=$ relative risk, $\mathrm{Cl}=$ confidence interval, cohort, $\mathrm{RCT}=$ randomized controlled trial.

\section{Secondary outcomes}

Pooled analysis demonstrated patients treated with primary surgical experienced an increased disease free survival (DFS) probability compared with non-surgical treatment, with a RR of $1.20\left(95 \% \mathrm{Cl}=1.05\right.$ to $\left.1.37 ; \mathrm{I}^{2}=0 \%\right)$ (Fig. $\left.3 \mathrm{~A}\right)$. However, the results of TSA indicated that the cumulative Z-curve just reached the conventional boundary, and did not cross the trial sequential monitoring boundary (Fig. 3B). The estimated required information size to cross the boundary for conventional and trial sequential monitoring was 3367 randomized patients.

Pooled estimates indicated compared to non-surgical treatment, initial surgical significantly lowered larynx preservation, with a RR of 0.48 (95\% $\mathrm{Cl}=0.33$ to $0.70 ; \mathrm{I}^{2}=73 \%$ ) (Fig. $\left.4 \mathrm{~A}\right)$. TSA analysis shown the cumulative Z-curve crossed the boundary for conventional and trial sequential monitoring (Fig. 4B).

\section{Meta-regression analysis, publication bias, and GRADE}

A meta-regression analysis shown that simple size significantly inflected effect size $(P=0.038)($ Fig. $5 D)$, which a trend towards a greater and more conform declines in survival probability was observed among patients received surgical management. Whereas year of publication $(P=$ 0.402), percentage of male $(P=0.931)$, mean age $(P=0.893)$, percentage of T4 stage $(P=0.941)$, percentage of positive lymph node $(P=0.556)$, percentage of stagelV $(P=0.278)$, percentage of pyriform sinus $(P=0.144)$, and mean follow-up time $(P=0.556)$ did not significantly alter effect size, respectively (Fig. 5A, B, C, E, F, G, H and I). There was no evidence of publication bias for the primary outcome (OS) on inspection of the funnel plot (FigureS3) or from the Harbord test, 0.67 . The GRADE level of evidence for OS and larynx preservation was very low and the level of evidence for DFS was low. The results was presented in the 'summary of findings' (Table 3). 


\section{Outcomes for advanced hypopharyngeal cancer}

Patient or population: Patients with advanced hypopharyngeal cancer Intervention: Surgery Comparison: Non-surgery

\begin{tabular}{|c|c|c|c|c|c|}
\hline \multirow[t]{2}{*}{ Outcomes } & \multicolumn{2}{|c|}{ Illustrative comparative risks* $(95 \% \mathrm{Cl})$} & \multirow{2}{*}{$\begin{array}{l}\text { Relative effect } \\
(95 \% \mathrm{Cl})\end{array}$} & \multirow{2}{*}{$\begin{array}{l}\text { No of Participants } \\
\text { (studies) }\end{array}$} & \multirow{2}{*}{$\begin{array}{l}\text { Quality of the evidence } \\
\text { (GRADE) }\end{array}$} \\
\hline & Assumed risk & Corresponding risk & & & \\
\hline & Control & Outcomes & & & \\
\hline \multirow[t]{4}{*}{ Overall Survival } & \multicolumn{2}{|c|}{ Study population } & \multirow{4}{*}{$\begin{array}{l}\text { RR } 1.04 \\
(0.94 \text { to } 1.15)\end{array}$} & \multirow{4}{*}{$\begin{array}{l}2539 \\
\text { (17 studies) }\end{array}$} & \multirow{4}{*}{$\begin{array}{l}\oplus \Theta \Theta \Theta \\
\text { very low }{ }^{1}\end{array}$} \\
\hline & 422 per 1000 & 439 per 1000 (397 to 485$)$ & & & \\
\hline & Moderate & & & & \\
\hline & 417 per 1000 & 434 per 1000 (392 to 480$)$ & & & \\
\hline \multirow[t]{4}{*}{ Disease-free Survival } & \multicolumn{2}{|c|}{ Study population } & \multirow{4}{*}{$\begin{array}{l}\text { RR } 1.2 \\
(1.05 \text { to } 1.37)\end{array}$} & \multirow{4}{*}{$\begin{array}{l}1200 \\
\text { (11 studies) }\end{array}$} & \multirow{4}{*}{$\begin{array}{l}\oplus \oplus \Theta \Theta \\
\text { low }\end{array}$} \\
\hline & 371 per 1000 & 446 per 1000 (390 to 509$)$ & & & \\
\hline & \multicolumn{2}{|l|}{ Moderate } & & & \\
\hline & 367 per 1000 & 440 per 1000 (385 to 503 ) & & & \\
\hline \multirow[t]{5}{*}{ Larynx Preservation } & Study populati & & \multirow{5}{*}{$\begin{array}{l}\text { RR } 0.48 \\
(0.33 \text { to } 0.7)\end{array}$} & \multirow{5}{*}{$\begin{array}{l}1195 \\
\text { (10 studies) }\end{array}$} & \multirow{5}{*}{$\begin{array}{l}\oplus \ominus \ominus \ominus \\
\text { very low }\end{array}$} \\
\hline & 550 per 1000 & 264 per 1000 (182 to 385 ) & & & \\
\hline & \multicolumn{2}{|l|}{ Moderate } & & & \\
\hline & 372 per 1000 & 179 per 1000 (123 to 260$)$ & & & \\
\hline & 368 per 1000 & 408 per 1000 (361 to 460$)$ & & & \\
\hline \multicolumn{6}{|c|}{$\begin{array}{l}\text { *The basis for the assumed risk (e.g. the median control group risk across studies) is provided in footnotes. The corresponding risk (and its } \\
95 \% \text { confidence interval) is based on the assumed risk in the comparison group and the relative effect of the intervention (and its } 95 \% \mathrm{Cl} \text { ). } \\
\mathrm{Cl} \text { : Confidence interval; RR: Risk ratio; }\end{array}$} \\
\hline \multicolumn{6}{|c|}{$\begin{array}{l}\text { GRADE Working Group grades of evidence } \\
\text { High quality: Further research is very unlikely to change our confidence in the estimate of effect. } \\
\text { Moderate quality: Further research is likely to have an important impact on our confidence in the estimate of effect and may change the } \\
\text { estimate. } \\
\text { Low quality: Further research is very likely to have an important impact on our confidence in the estimate of effect and is likely to change the } \\
\text { estimate. } \\
\text { Very low quality: We are very uncertain about the estimate. }\end{array}$} \\
\hline
\end{tabular}

\section{Discussion}

The current meta-analysis, which involved two RCTs, comprising 286 patients, and fifteen retrospective cohorts, including 1987 patients, compared primary surgical with non-surgical administration. The summary results confirmed that between initial surgical and non-surgical management have similar overall survival (RR $1.04, \mathrm{Cl}=0.94$ to $1.15 ; I^{2}=5 \%$ ), with TSA inconclusive. Subgroup analysis verified that the finding were generally conform, regardless of study location, study design, age, and study quality. Additionally, compared to non-surgical treatment, the primary surgical significantly improved disease free survival (RR $1.20, \mathrm{Cl}=1.05$ to $1.37 ; \mathrm{I}^{2}=0$ ), with TSA inconclusive. Noteworthily, non-surgical administration did have a beneficial effect on larynx preservation, with TSA conclusive.

Recently systematic reviews illustrated management of advanced hypopharyngeal carcinoma ${ }^{28}$, while it did not statistically integrate available data to analyze whether there exist significant efficacy difference between primary surgical and non-surgical therapy or not. Meanwhile, it did not incorporate three additional new trials ${ }^{12,19,17}$, with two of them as lager simple retrospective cohorts. In 2018, Kim et al., using the latest population-based database (Surveillance, Epidemiology, and End Results (SEER)), analyzed the comparative effectiveness of primary surgical and non-surgical therapy for advanced hypopharyngeal cancer in the contemporary era, and indicated that treatment outcomes in the chemoradiotherapy group were comparable to that of the surgical group for locally advanced hypophagyngeal cancer ${ }^{19}$. Sequentially, Chung et al. performed a multicenter trials comparing induction chemotherapy with (chemo) radiotherapy, definitive chemoradiotherapy and surgerybased therapy to assess the relative efficacy outcomes on patients with locally advanced hypopharyngeal squamous cell carcinoma, which 
verified that whether induction chemotherapy followed by (chemo) radiotherapy or definitive chemoradiotherapy showed a comparable overall survival rate to surgery-based therapy ${ }^{12}$.

To the best of our knowledge, this is first comprehensive meta-analysis to summarize all current studies focusing on comparing the relative effectiveness of between primary surgical and non-surgery therapy in advanced hypopharyngeal carcinoma. The meta-analysis and systematic review have a number of methodological strengths. Firstly, the protocol of this study was registered on PROSPERO. A prior-registered protocol may enhance the quality and transparency of meta-analyses. Secondly, predefined subgroup was performed to explore that specific patients can benefit from initial surgical or non-surgical treatment. Additionally, meta-regression was conducted to investigate the potential modifiers on outcomes. Thirdly, TSA was used to evaluate the risk of random errors (false discoveries), and its results support the contention that a $15 \%$ relative decrease or increase in incidence of events can be confidently removed. Finally, we analyzed the level of evidence using the GRADE method, which ranks evidence of clinical outcomes as high, moderate, low, or very low quality.

Our meta-analysis confirmed that the primary surgical compared to non-surgical management does not significantly improve overall survival in advanced hypopharyngeal cancer. However, our TSA presented that the Z-curve not only did not cross the conventional boundary and trial sequential monitoring boundary for benefit, but also did not enter the futility area, which show that conclusive evidence is not established and more researches were needed to affirm the results. Subgroup analysis verified that the result were generally consistent, regardless of study location, study design, age, and study quality. In additional, we found that the primary surgical can increase disease free survival probability compared with non-surgical administration, whereas TAS result showed that the cumulative Z-curve did not cross the trial sequential monitoring boundary. The result indicated that the required information size was not reached, the evidence achieving a credible conclusion was insufficient and future clinical researches were needed to affirm. It is worth mentioning that non-surgical management did have a positive effect on larynx preservation, with TSA conclusive. Regarding larynx preservation, this evidence is firm conclusion, and that further trials are not required.

A meta-regression analysis using restricted maximum likelihood estimators find that simple size had potential influence on treatments when the simple size in a trial was used as a moderating variable. Simple size possess a significant declining trend on effect size, that is to say, the primary surgical will be inferior to non-surgical treatment with the increase of sample size in advanced hypopharyngeal carcinoma. The finding may be explained that Kim et al. trial with maximum sample size in all included studies account for $22.1 \%$ overall estimate from forest plot and exert an observable impact on effect size. What's more, the result imply that further more trials are required, in accordance with the results of our TSA with regard to overall survival and disease free survival. Hence, further large and perspective RCTs were need to clarify the relative efficacy between surgery-based therapy and non-surgical treatment on survival outcome.

Currently, in the context of the global trend toward organ-preserving treatment (non-surgical treatment), definitive chemoradiotherapy has obtained increasing prevalence as the definitive therapy in hypopharyngeal cancer. Given we cannot come to a clear conclusion that non-surgical treatment is non-inferior to surgery-based therapy in terms of survival outcome, thus it is of great importance to identify reliable and convenient clinical factors/markers to screen out which subset of patients with advanced hypopharyngeal cancer is suitable to organ-preserving treatment using definitive chemoradiotherapy with surgery reserved for salvage, and optimize non-surgical therapeutic strategies. Induction chemotherapy appears to serve as mediator, as studies revealed that a response to incipient chemotherapy predicted a response to subsequent treatment in the advanced head and neck cancer, including oral cavity, oropharynx, laryngeal and hypopharynx ${ }^{29-31}$. In additional, compared to non-responders, responders had significantly favorable survival. The concept was also adopted in the Veterans Affairs Laryngeal Cancer Study ${ }^{7}$. On account of hypopharynx cancer accounting for minor part in above trials, the effect of response to induction chemotherapy only in advanced hypopharynx cancer patients to determine organ-preserving treatment are awaited to further research. In recent years, human papilloma virus (HPV) infection have been recognized as risk factors for HNC, including hypopharynx. Several trials indicated that HPV positive patients were sensitive to radiotherapy and chemotherapy as well as showed superior survival ${ }^{32,33}$.Maybe HPV status can be a predictor to select non-surgical treatment. Future larger prospective studies with adequately powered are warranted to clarify issues.

Several limitations should be noted in our study. First, the number of retrospective cohorts was relatively large, and there were only two old RCTs published in the early 1980s. As for retrospective trials, selection bias is very likely due to no randomisation between the treatment strategies. In regard to RCTs, neither trials stated blinding for participants, personnel or the outcome assessment, which augmented the bias risk of performance and detection. On the basis of above reasons, GRADE judged the certainty of the body of evidence as low or very for each outcome. Hence, there is a need for large, multi-centered RCTs to support the current results. Second, though we found that non-surgical administration can remarkably improve larynx preservation, the obvious heterogeneity was observed. This is because marked heterogeneity existed across the included studies in terms of the different types of chemotherapy received, as well as the type and doses of radiotherapy. But almost all studies there is a clear superiority with non-surgical treatments in terms of preserving a functional larynx. Third, a large proportion of eligible trials had a small sample size, with only 6 of the 17 trials containing a sample size of larger than 100 patients. Just as our findings of meta-regression analysis and TSA, the small sample sizes may have influence on treatment effects, indicating a need for large and perspective researches. Fourth, the safety of non-surgical administration cannot be detected on account of insufficient data. Most of the included studies did not thoroughly evaluated the adverse effect of organ preservation treatment in locally advanced hypopharyngeal cancer, unlike in carcinoma of the

Page 8/16 
larynx, which hindered a definite conclusion regarding optimal treatment regimen ${ }^{34}$. Further well-designed researches are warranted to resolve these issues.

\section{Conclusion}

The results of our meta-analysis indicated treatment outcomes in non-surgical therapy were comparable to that of surgery-based therapy for advanced-stage hypopharyngeal cancer, which makes larynx preservation feasible. It can be served as an alternative approach in patients who are unfit for or refuse surgery. On account of inconclusive evidence from TSA, further prospective investigations comparing modern non-surgical management with modern surgical techniques remain necessary.

\section{Abbreviations}

$\mathrm{TSA}=$ trial sequential analysis, GRADE= The Grading of Recommendations Assessment Development and Evaluation, RR= relative risk, $\mathrm{Cl}=$ confidence interval, OS=overall survival, DFS= disease free survival, WHO=World Health Organization, HNC=head and neck cancers, PRISMA=Preferred Reporting Items for Systematic Reviews and Meta-analyses, PICOS =participants, interventions, comparators, outcomes, and study design, RCTs= randomized controlled trials, SEER=Surveillance, Epidemiology, and End Results, HPV=human papilloma virus, NA=not available, $\mathrm{SD}=$ standard deviation, No.= number of participants, $\mathrm{RC}=$ retrospective cohort, $\mathrm{RT}=$ radiotherapy, $\mathrm{CRT}=\mathrm{chemoradiotherapy,} \mathrm{CT}=$ chemotherapy, REC=representative of exposed cohort , SNC=selection of nonexposed cohort, $\mathrm{AE}=$ ascertainment of exposed, $\mathrm{AOI}=\mathrm{absence}$ of outcome of interest.

\section{Declarations}

\section{Ethics approval and consent to participate}

Not applicable.

\section{Consent for publication}

Not applicable.

\section{Availability of data and material}

There is no additional data are available.

\section{Competing interests}

The authors declare that they have no competing interests.

\section{Funding}

Not applicable.

\section{Authors' contributions}

Study concept and design: GLL, JC, LPW, XJT, JSL and HY. Acquisition of data: GLL, JSP and ZC. Analysis and interpretation of data: JC, HYH, GLL and LPW. Drafting of the manuscript: XJT and WQC. Critical revision of the manuscript for important intellectual content: GLL, JSL and HY. Statistical analysis: GLL, JSP and LPW. Administrative, technical, and material support: HY and LPW. Study supervision: GLL, JC, XJT, JSL and HY. All authors have read and approved the manuscript for publication.

\section{Authors' information}

1 Department of Head and Neck Surgical, Affiliated Cancer Hospital \& Institute of Guangzhou Medical University, Guangzhou, 510095, Guangdong Province, PR China.

2 Department of otorhinolaryngology head and neck surgery, The First Affiliated Hospital of Hainan Medical University, Haikou, 570102 , Hainan Province, PR China

3 Department of Pathology, Affiliated Cancer Hospital \& Institute of Guangzhou Medical University, Guangzhou, 510095, Guangdong Province, PR China. 
4 Department of Radiology, Affiliated Cancer Hospital \& Institute of Guangzhou Medical University, Guangzhou, 510095, Guangdong Province, PR China.

5 Department of Intensive Care Unit, Shunde Hospital, Southern Medical University (The First people's hospital of Shunde), Foshan, 528308, Guangdong Province, PR China.

\section{Acknowledgements}

Not applicable.

\section{References}

1. Cooper JS, Porter K, Mallin K, Hoffman HT, Weber RS, Ang KK, Gay EG, Langer CJ: National Cancer Database report on cancer of the head and neck: 10-year update. Head \& neck 2009, 31(6):748-758.

2. Karia PS, Morgan FC, Califano JA, Schmults CD: Comparison of Tumor Classifications for Cutaneous Squamous Cell Carcinoma of the Head and Neck in the 7th vs 8th Edition of the AJCC Cancer Staging Manual. JAMA dermatology 2018, 154(2):175-181.

3. Gourin CG, Terris DJ: Carcinoma of the hypopharynx. Surgical oncology clinics of North America 2004, 13(1):81-98.

4. Buckley JG, MacLennan K: Cervical node metastases in laryngeal and hypopharyngeal cancer: a prospective analysis of prevalence and distribution. Head \& neck 2000, 22(4):380-385.

5. Petersen JF, Timmermans AJ, van Dijk BAC, Overbeek LIH, Smit LA, Hilgers FJM, Stuiver MM, van den Brekel MWM: Trends in treatment, incidence and survival of hypopharynx cancer: a 20-year population-based study in the Netherlands. European archives of oto-rhinolaryngology : official journal of the European Federation of Oto-Rhino-Laryngological Societies 2018, 275(1):181-189.

6. Lefebvre JL, Pointreau Y, Rolland F, Alfonsi M, Baudoux A, Sire C, de Raucourt D, Malard O, Degardin M, Tuchais C et al: Induction chemotherapy followed by either chemoradiotherapy or bioradiotherapy for larynx preservation: the TREMPLIN randomized phase II study. Journal of clinical oncology : official journal of the American Society of Clinical Oncology 2013, 31(7):853-859.

7. Wolf GT, Fisher SG, Hong WK, Hillman R, Spaulding M, Laramore GE, Endicott JW, McClatchey K, Henderson WG: Induction chemotherapy plus radiation compared with surgical plus radiation in patients with advanced laryngeal cancer. The New England journal of medicine 1991, 324(24):1685-1690.

8. Adelstein DJ, Li Y, Adams GL, Wagner H, Jr., Kish JA, Ensley JF, Schuller DE, Forastiere AA: An intergroup phase III comparison of standard radiation therapy and two schedules of concurrent chemoradiotherapy in patients with unresectable squamous cell head and neck cancer. Journal of clinical oncology: official journal of the American Society of Clinical Oncology 2003, 21(1):92-98.

9. Altundag O, Gullu I, Altundag K, Yalcin S, Ozyar E, Cengiz M, Akyol F, Yucel T, Hosal S, Sozeri B: Induction chemotherapy with cisplatin and 5fluorouracil followed by chemoradiotherapy or radiotherapy alone in the treatment of locoregionally advanced resectable cancers of the larynx and hypopharynx: results of single-center study of 45 patients. Head \& neck 2005, 27(1):15-21.

10. Chan JY, Wei WI: Current management strategy of hypopharyngeal carcinoma. Auris, nasus, larynx 2013, 40(1):2-6.

11. Beauvillain C, Mahe M, Bourdin S, Peuvrel P, Bergerot P, Riviere A, Vignoud J, Deraucourt D, Wesoluch M: Final results of a randomized trial comparing chemotherapy plus radiotherapy with chemotherapy plus surgical plus radiotherapy in locally advanced resectable hypopharyngeal carcinomas. The Laryngoscope 1997, 107(5):648-653.

12. Chung EJ, Jeong WJ, Jung YH, Kwon SK, Kwon TK, Ahn SH, Sung MW, Keam B, Heo DS, Kim JH et al: Long-term oncological and functional outcomes of induction chemotherapy followed by (chemo)radiotherapy vs definitive chemoradiotherapy vs surgical-based therapy in locally advanced stage III/IV hypopharyngeal cancer: Multicenter review of 266 cases. Oral oncology 2019, 89:84-94.

13. Harris BN, Biron VL, Donald P, Farwell DG, Luu QC, Bewley AF, Chen AM, Daly ME: Primary Surgical vs Chemoradiation Treatment of Advanced-Stage Hypopharyngeal Squamous Cell Carcinoma. JAMA otolaryngology- head \& neck surgical 2015, 141(7):636-640.

14. Hung SK, Chen H, Hsieh C, Hsu W, Chang K, Liu D et al.Treatment of advanced hypopharyngeal cancer-comparison of two modalities. Tzu Chi Med J 2006; 18:15-21.

15. Huang WY, Jen YM, Chen CM, Su YF, Lin CS, Lin YS, Chang YN, Chao HL, Lin KT, Chang LP: Intensity modulated radiotherapy with concurrent chemotherapy for larynx preservation of advanced resectable hypopharyngeal cancer. Radiation oncology (London, England) $2010,5: 37$.

16. Jang JY, Kim EH, Cho J, Jung JH, Oh D, Ahn YC, Son YI, Jeong HS: Comparison of Oncological and Functional Outcomes between Initial Surgical versus Non-Surgical Treatments for Hypopharyngeal Cancer. Annals of surgical oncology 2016, 23(6):2054-2061.

17. Kim S, Wu HG, Heo DS, Kim KH, Sung MW, Park Cl: Advanced hypopharyngeal carcinoma treatment results according to treatment modalities. Head \& neck 2001, 23(9):713-717.

18. Kim JW, Kim MS, Kim SH, Kim JH, Lee CG, Kim GE, Keum KC: Definitive Chemoradiotherapy Versus Surgical Followed by Adjuvant Radiotherapy in Resectable Stage III/IV Hypopharyngeal Cancer. Cancer research and treatment : official journal of Korean Cancer

Page 10/16 
Association 2016, 48(1):45-53.

19. Kim YJ, Lee R: Surgical vs. radiotherapy for locally advanced hypopharyngeal cancer in the contemporary era: A population-based study. Cancer medicine 2018, 7(12):5889-5900.

20. Lajtman Z, Manestar D: A comparison of surgical and radiotherapy in the management of advanced pyriform fossa carcinoma. Clinical otolaryngology and allied sciences 2001, 26(1):59-61.

21. Lee MS, Ho HC, Hsiao SH, Hwang JH, Lee CC, Hung SK: Treatment results and prognostic factors in locally advanced hypopharyngeal cancer. Acta oto-laryngologica 2008, 128(1):103-109.

22. Lefebvre JL, Chevalier D, Luboinski B, Kirkpatrick A, Collette L, Sahmoud T: Larynx preservation in pyriform sinus cancer: preliminary results of a European Organization for Research and Treatment of Cancer phase III trial. EORTC Head and Neck Cancer Cooperative Group. Journal of the National Cancer Institute 1996, 88(13):890-899.

23. Reis I, Aguiar A, Alzamora C, Ferreira C, Castro V, Soares A, Lobao M: Locally advanced hypopharyngeal squamous cell carcinoma: singleinstitution outcomes in a cohort of patients curatively treated either with or without larynx preservation. Radiologia brasileira 2016, 49(1):2125.

24. Slotman BJ, Kralendonk JH, Snow GB, Tiwari RM, Karim AB: Surgical and postoperative radiotherapy and radiotherapy alone in T3-T4 cancers of the pyriform sinus. Treatment results and patterns of failure. Acta oncologica (Stockholm, Sweden) 1994, 33(1):55-60.

25. Vandersteen C, Benezery K, Chamorey E, Ettaiche M, Dassonville O, Poissonnet G, Riss JC, Pierre CS, Hannoun-Levi JM, Chand ME et al: Contemporary therapeutic management of locally advanced hypopharyngeal cancer: oncologic and functional outcomes - a report on 100 cases. Acta oto-laryngologica 2015, 135(2):193-200.

26. Zelefsky MJ, Kraus DH, Pfister DG, Raben A, Shah JP, Strong EW, Spiro RH, BosI GJ, Harrison LB: Combined chemotherapy and radiotherapy versus surgical and postoperative radiotherapy for advanced hypopharyngeal cancer. Head \& neck 1996, 18(5):405-411.

27. Zhang YX, Peng HH, Zhang XX, Zhao JD, Wu WM, Wang JL, Huang DL, Zong L, Chen LW, Liu CQ et al: [A retrospective study on combined modality therapy with or without surgical for advanced hypopharyngeal squamous cell carcinoma: an analysis of 119 cases]. Zhonghua er bi yan hou tou jing wai ke za zhi = Chinese journal of otorhinolaryngology head and neck surgical 2018, 53(5):352-358.

28. Habib A: Management of advanced hypopharyngeal carcinoma: systematic review of survival following surgical and non-surgical treatments. The Journal of laryngology and otology 2018, 132(5):385-400.

29. Ensley J, Crissman J, Kish J, Jacobs J, Weaver A, Kinzie J, Cummings G, Al-Sarraf M: The impact of conventional morphologic analysis on response rates and survival in patients with advanced head and neck cancers treated initially with cisplatin-containing combination chemotherapy. Cancer 1986, 57(4):711-717.

30. Rooney M, Kish J, Jacobs J, Kinzie J, Weaver A, Crissman J, Al-Sarraf M: Improved complete response rate and survival in advanced head and neck cancer after three-course induction therapy with 120-hour 5-FU infusion and cisplatin. Cancer 1985, 55(5):1123-1128.

31. Schuller DE, Wilson HE, Smith RE, Batley F, James AD: Preoperative reductive chemotherapy for locally advanced carcinoma of the oral cavity, oropharynx, and hypopharynx. Cancer 1983, 51(1):15-19.

32. Chen AM, Felix C, Wang PC, Hsu S, Basehart V, Garst J, et al. Reduced-dose radiotherapy for human papillomavirus-associated squamouscell carcinoma of the oropharynx: a single-arm, phase 2 study. The Lancet Oncology. 2017;18:803-11.

33. Gillison ML, Trotti AM, Harris J, Eisbruch A, Harari PM, Adelstein DJ, et al. Radiotherapy plus cetuximab or cisplatin in human papillomavirus-positive oropharyngeal cancer (NRG Oncology RTOG 1016): a randomised, multicentre, non-inferiority trial. Lancet (London, England). 2019;393:40-50.

34. Takes RP, Strojan P, Silver CE, Bradley PJ, Haigentz M, Jr., Wolf GT, Shaha AR, Hartl DM, Olofsson J, Langendijk JA et al: Current trends in initial management of hypopharyngeal cancer: the declining use of open surgical. Head \& neck 2012, 34(2):270-281.

35. Cui J, Tang D, Chen Z: Impact of Early versus Late Initiation of Renal Replacement Therapy in Patients with Cardiac Surgical-Associated Acute Kidney Injury: Meta-Analysis with Trial Sequential Analysis of Randomized Controlled Trials. 2018, $2018: 6942829$.

36. Liberati A, Altman DG, Tetzlaff J, Mulrow C, Gotzsche PC, loannidis JP, Clarke M, Devereaux PJ, Kleijnen J, Moher D: The PRISMA statement for reporting systematic reviews and meta-analyses of studies that evaluate healthcare interventions: explanation and elaboration. BMJ (Clinical research ed) 2009, 339:b2700.

37. Higgins JP, Altman DG, Gotzsche PC, Juni P, Moher D, Oxman AD, Savovic J, Schulz KF, Weeks L, Sterne JA: The Cochrane Collaboration's tool for assessing risk of bias in randomised trials. BMJ (Clinical research ed) 2011, 343:d5928.

38. Brok J, Thorlund K, Gluud C, Wetterslev J: Trial sequential analysis reveals insufficient information size and potentially false positive results in many meta-analyses. Journal of clinical epidemiology 2008, 61(8):763-769.

\section{Supplementary Figure And Table Legends}

FigureS1. Risk of bias graph

Page $11 / 16$ 
FigureS2. Risk of bias summary.

FigureS3. Assessment of publication bias using a funnel plot.

TableS1. Treatment modalities of the studies included in the meta-analysis.

TableS2. Quality Assessment With Newcastle Ottawa Scale for cohort study

TableS3. Meta-regression analysis analyzing the potential confounders for outcome

\section{Figures}

6095 records identified through datebase searching

(PubMed 2341 the Cochrane Library 552 ISI web of knowledge 2760 Embase 442)

3012 records after

duplicates removed

3012 records screened
title and abstract

2924 unrelated studies

were excluded

88 full texts assesed

for eligibility

$$
\begin{gathered}
71 \text { Full texts excluded } \\
\text { with reasons } \\
\text { - reviews } 17 \\
\text {-case reports } 5 \\
\text {-letters to the editor } 9 \\
\text {-editorials } 6 \\
\text { - the outcome of interests } \\
\text { was not reported } 34
\end{gathered}
$$

17 studies included in meta-analysis

\section{Figure 1}

Flow diagram of literature search and selection process of the studies 
Huang 2010

Jang 2016

Kim 2001

Kim 2016

Kim 2018

Lajtman 2001

Lee 2008

Lefebvre 1996

Reis 2016

Slotmam 1994

Vandersteen 2015

Zelefsky 1996

Zhang 2018

$\begin{array}{lr}18 & 47 \\ 63 & 139\end{array}$

$8 \quad 45 \quad 1.9 \%$

$2.15[1.04,4.45]$

$1.07[0.81,1.40]$

$1.54[1.00,2.38]$

$0.79[0.35,1.74]$

$1.11[0.58,2.13]$

$1.11[0.58,2.13]$

$1.11[0.81,1.53]$

$1.36[0.72,2.58]$

$0.95[0.66,1.37]$

$0.86[0.71,1.04]$

$1.36[0.43,4.34]$

$1.24[0.70,2.19]$

$0.97[0.77,1.24]$

$1.13[0.69,1.83]$

$1.15[0.30,4.31]$

$1.15[0.30,4.31]$

$0.63[0.34,1.19]$
$1.52[0.50,4.60]$

$1.20[0.83,1.74]$

Total $(95 \% \mathrm{Cl})$
Total events

666

$1.04[0.94,1.15]$

M-H. Random. $95 \%$ Cl

Heterogeneity: Tau $^{2}=0.00 ; \mathrm{Chi}^{2}=16.87 \mathrm{df}=16(\mathrm{P}=0.39): \mathrm{I}^{2}=5 \%$

Test for overall effect: $Z=0.78(P=0.44)$

B Cumulative

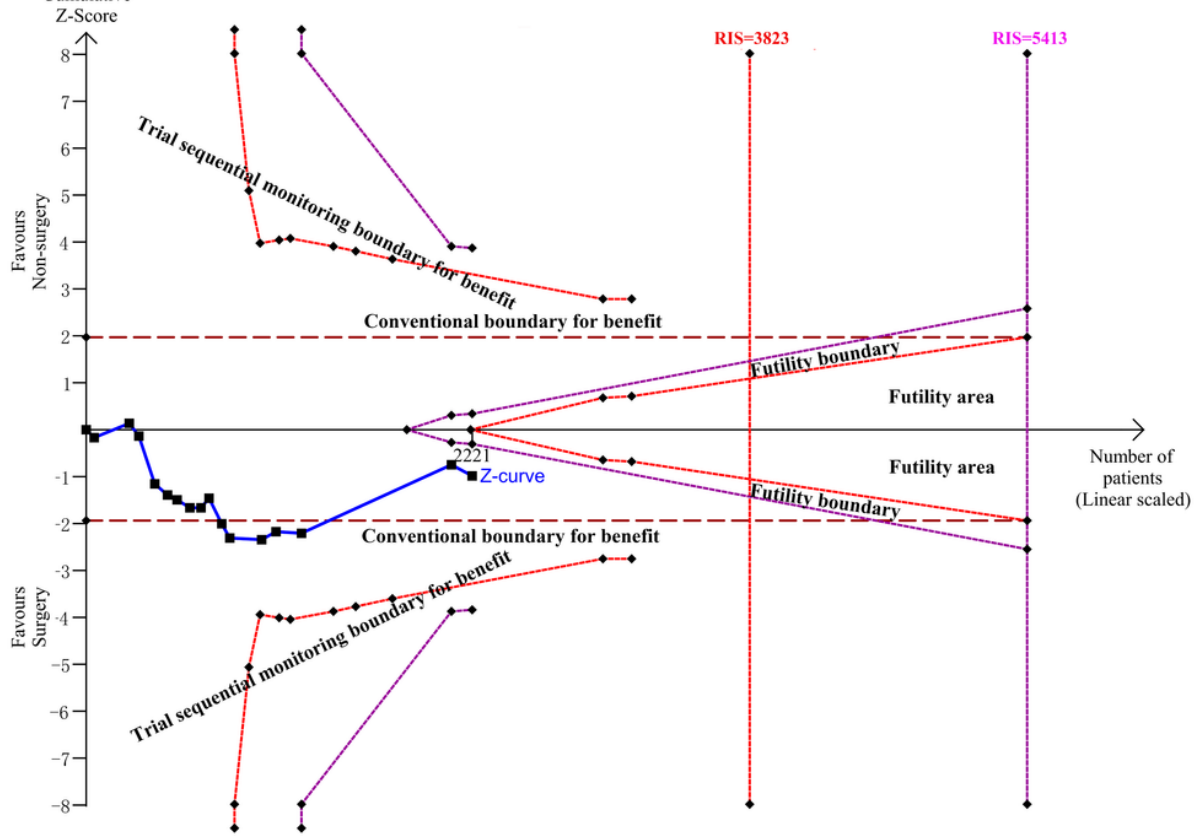

Figure 2

(A) Forest plot of studies reporting overall survival outcome. (B) Random-effect model of trial sequential analysis for overall survival outcome: a relative risk of 1.04 , two-sided boundary, incidence of $40.9 \%$ in surgical group, incidence of $37.3 \%$ in non-surgical group, a low bias estimated relative risk reduction of $15 \%$, a of $5 \%$, power of $90 \%$ were set. The required information size was calculated as 3823 . The cumulative Z-curve did not cross the conventional boundary for benefits and did not enter the futility boundary. 


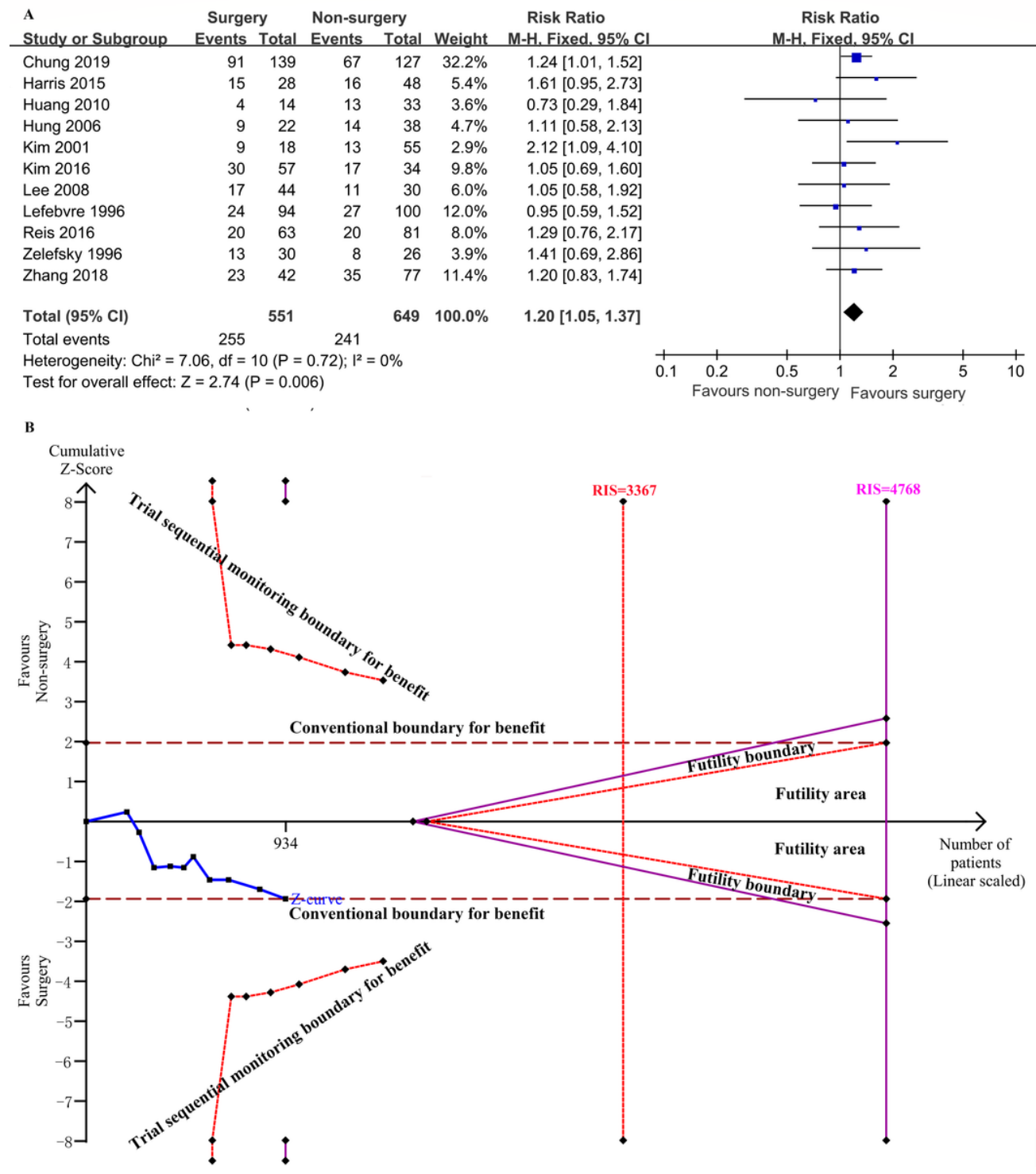

Figure 3

(A) Forest plot of studies showing disease free survival outcome. (B) Random-effect model of trial sequential analysis for disease free survival outcome: a relative risk of 1.20, two-sided boundary, incidence of $44.1 \%$ in surgical group, incidence of $34.8 \%$ in non-surgical group, a low bias estimated relative risk reduction of $15 \%$, a of $5 \%$, power of $90 \%$ were set. The required information size was calculated as 3367 . The cumulative Z-curve just reached the conventional boundary and did not cross the trial sequential monitoring boundary. 
Study or Subgroup Events Total Events Total Weight M-H. Random. 95\%

Chung 2019

Huang 2010

$62 \quad 139$

$\begin{array}{rrr}91 & 127 & 22.2 \%\end{array}$

Jang 2016

$\begin{array}{rrrrr}0 & 14 & 13 & 33 & 1.8 \% \\ 35 & 70 & 97 & 107 & 21.8 \%\end{array}$

Kim 2001

Kim 2016

Lee 2008

Lefebvre 1996

Vandersteen 2015

Zelefsky 1996

Zhang 2018

Total $(95 \% \mathrm{Cl})$

Total events

$35 \quad 70$

$0.62[0.50,0.77]$

$0.08[0.01,1.32]$

$0.55[0.43,0.70]$

$0.09[0.01,1.42]$

$0.34[0.22,0.51]$

$0.04[0.00,0.68]$

$0.01[0.00,0.24]$

$0.10[0.01,1.62]$

$1.52[0.50,4.60]$

$0.70[0.50,0.98]$

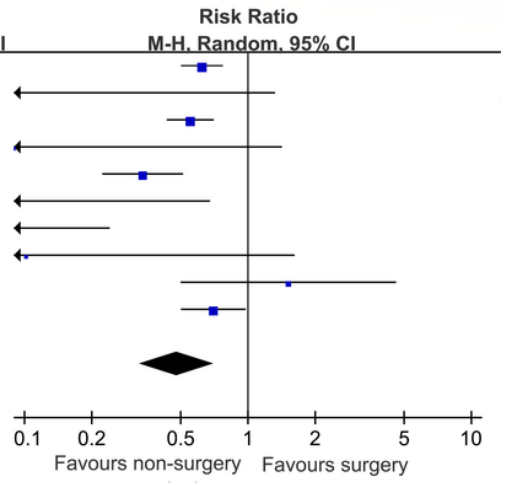

Test for ovell affect: $\mathrm{Z}=3.75(\mathrm{P}=0.0002)$

B

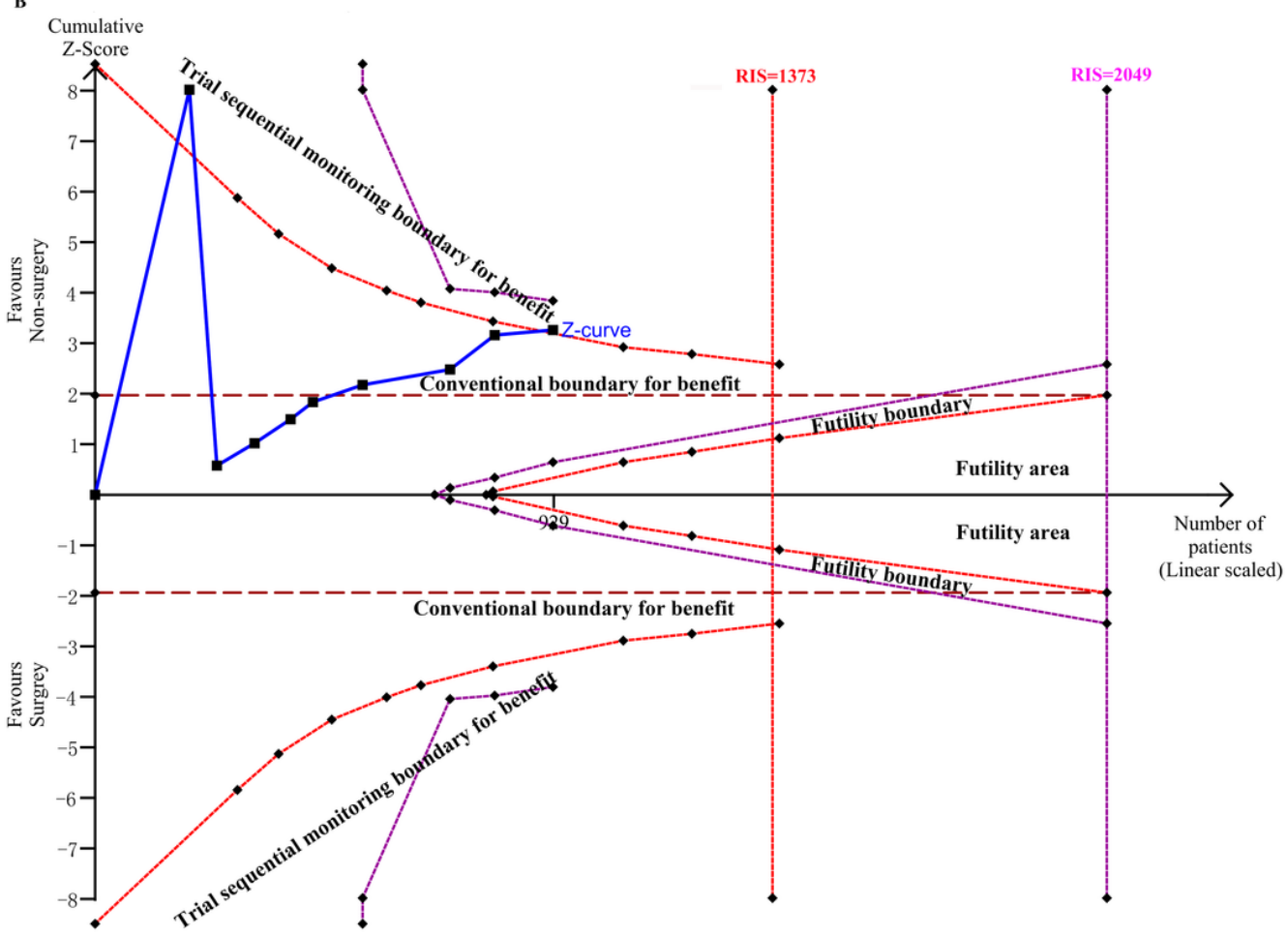

Figure 4

(A) Forest plot of studies displaying larynx preservation outcome. (B) Random-effect model of trial sequential analysis for larynx preservation outcome: a relative risk of 0.40 , two-sided boundary, incidence of $19.8 \%$ in surgical group, incidence of $46.5 \%$ in non-surgical group, a low bias estimated relative risk reduction of $15 \%$, a of $5 \%$, power of $90 \%$ were set. The required information size was calculated as 1373 . The cumulative Z-curve crossed conventional boundary and the trial sequential monitoring boundary the boundary 

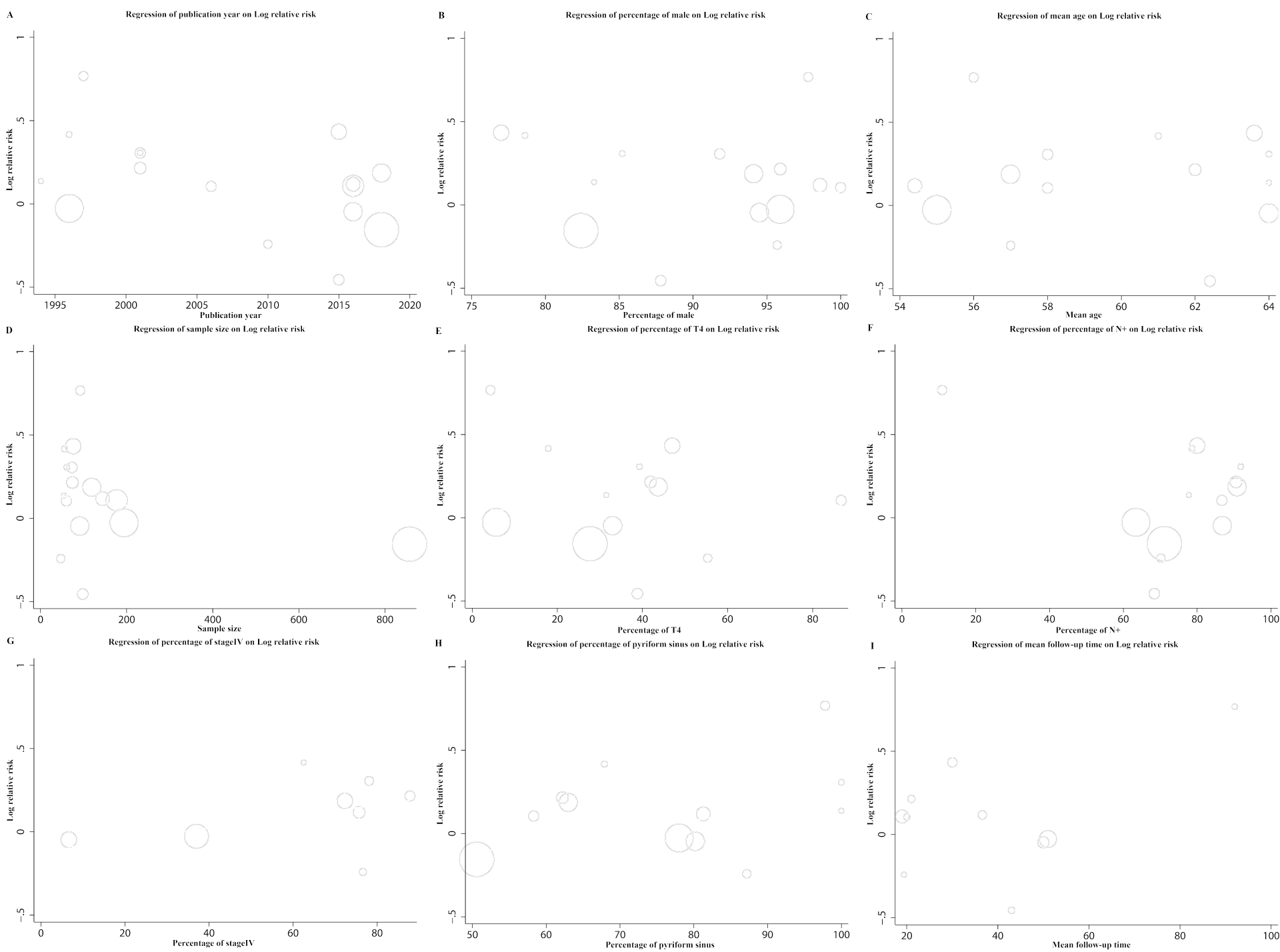

Figure 5

Random-effects meta-regression analyses showing the relationship between the study effect size and (A) publication year, (B) percentage of male, (C) mean age. (D)simple size, (E) percentage of T4, $(F)$ percentage of $N+,(G)$ percentage of stagelV, $(H)$ percentage of pyriform sinus, $(I)$ mean follow-up time. The size of the circles is inversely proportional to the size of the result study variance, so that more precise studies have larger circles.

\section{Supplementary Files}

This is a list of supplementary files associated with this preprint. Click to download.

- PRISMAchecklist.doc

- Figures3.tif

- FigureS1.tif

- Figures2.tif

- Tables2.docx

- Tables1.docx

- Tables3.docx 